\title{
Assessment of different infiltration equations for cultivated and pasture land
}

\author{
K.B. Patil, S.P. Nikam and V.N. Nale
}

Received : 03.02.2020; Revised : 03.03.2020; Accepted : 16.03.2020

See end of the Paper for authors' affiliation

Correspondence to :

S.P. Nikam

Department of Agricultural Engineering, College of Agriculture (MPKV), Dhule (M.S.) India Email: spnikam74@gmail.com
- ABSTRACT : The measure of infiltration of water into the soil is an important indication concerning: the efficiency of irrigation and drainage optimizing the availability of the water for plant improving the yield of the crop and minimizing the erosion. By knowing proper infiltration characteristics and intake capacity of soil, deep percolation losses can be prevented and proper utilization of water may take place. Keeping the importance of infiltration characteristics in mind the study of infiltration was taken. In this study most appropriate methods for determination of infiltration under different land uses were selected among most popular methods. Some of the wellknown equations are Kostiakov equation, Modified Kostiakov equation and Horton equation. These three equations were studied for the assessment infiltration equation. Assessment of these equations was done under different lands covers such as Cultivated land cover, Pasture land cover. From the analysis of the data, it is concluded that for cultivated land cover correlation coefficients for cumulative infiltration were found to be $0.9569,0.9687$ and 0.9724 for Kostiakov, Modified Kostiakov and Horton equation, respectively. As correlation co-efficient for Horton equation is higher, this equation was found best fit for cultivated land cover. Similarly, for pasture land cover the correlation co-efficients for cumulative infiltration were found to be $0.9876,0.9706$ and 0.9891 for Kostiakov, Modified Kostiakov and Horton equation, respectively. As correlation co-efficient for Horton equation is higher, this equation was found best fit for pasture land cover.

- KEY WORDS : Infiltration, Infiltration rate, Infiltration equation, Land use

- HOW TO CITE THIS PAPER : Patil, K.B., Nikam, S.P. and Nale, V.N. (2020). Assessment of different infiltration equations for cultivated and pasture land. Internat. J. Agric. Engg., 13(1) : 107-112, DOI: 10.15740/HAS/IJAE/13.1/107-112. Copyright@2020: Hind Agri-Horticultural Society. 